\title{
Ekphrastic Poetics: Fostering a Curriculum of Ecological Awareness \\ Through Poetic Inquiry
}

\author{
Andrejs Kulnieks \\ York University \\ Kelly Young \\ Trent University
}

\begin{abstract}
In this article, we outline the role of ekphrastic poetics in an ecological practice of poetic inquiry. Ekphrastic poetics, as a rhetorical device, involves one medium of art relating to another medium by unfolding its form and essence. Ultimately, our work involves a poetic response to an aesthetic form and it is through our ongoing collaborations that we are able to outline the importance of the poetic benefits of dwelling in natural places. We offer specific examples of how we engage in interpretive response activities that help to foster ecological habits of mind in teacher education.
\end{abstract}

Keywords: arts-informed; ekphrastic poetics; collaboration; poetic inquiry; ecology; curriculum

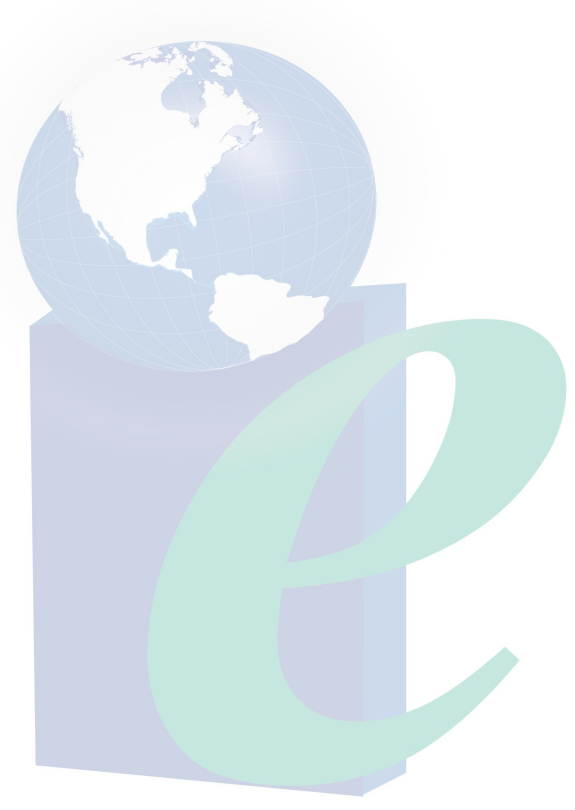




\section{Ekphrastic Poetics: Fostering a Curriculum of Ecological Awareness Through Poetic Inquiry}

The role of the imagination is not to resolve, not to point the way, not to improve. It is to awaken, to disclose the ordinarily unseen, unheard and unexpected. (Maxine Greene, 1995, p. 28)

Our article emerges from several knowledge sources as the authors bring together their experiences of researching and teaching in public and private systems of education as well as with undergraduate and graduate learners since 2000 . We bring together an interdisciplinary lens to curriculum theorizing and the importance of developing ecological habits of mind in teacher education with our research question: "How does one begin writing a poem that connects language, place, and intergenerational knowledge?" In teasing out the form, cadence, and malleable metaphors from an existing story, it is as if the poem asks the author to clarify the language of the story being communicated. We read widely in the areas of fiction and poetry, turning a focus toward an array of aesthetic forms to help deepen our relationship with language. Playing with form as one begins to write a poem is essential. By playing with form, we mean immersing oneself in it. By turning to the poetic form of ekphrastic poetics, an art form dating back to Classical Greece, we become involved in an act of poetic response to an aesthetic form through interpretive practices (Davis, Sumara, \& Luce-Kapler, 2000). Interpretive practices involve building relationships with the aesthetic forms through, among other things, conditioned writing activities. By conditioned writing practices we mean (a) spending time in the natural environments, (b) photographing our local ecosystem, and (c) drawing upon our memories of immersion in local landscapes and documenting these in stories/poems as we engage in mimesis.

In his 1595 Defense of Poetry, Sir Philip Sidney returned to Aristotle's notion of mimesis and suggested that poetry is the "art of imitation" (as cited in Duncan-Jones, 1989, p. 227). Learning to write poetry involves an immersion in forms, a process of mimesis and the imagination. Mimesis highlights a complex process of immersion in forms that can inform an imaginative relationship between writer and an aesthetic form involving the perception and imagination of the poet. Poetry, as with other art forms, "is not only a product of nature, but one of the creative instruments of nature in doing what it does. We are natura naturans, nature naturing" (Turner, 1985, p. 46). Etymologically, the word mimesis, from the Latin imitate-us, refers to a reproduction, a simulation, and a mimetical fictitious likeness of a phenomenon (The Oxford English Dictionary, 1989, p. 1378). However, ekphrastic poetics is more than imitation because it is also about interpreting self in relation to the ways in which forms are organized. We have found that by returning to an ancient aesthetic form such as ekphrastic poetics, we begin to theorize that poetry, as a particular form of mimesis, organizes human cognition while mediating experience and identity-formation (Davis et al., 2000). For language educators, ekphrastic poetics involves an act of poetic response to an aesthetic form.

We draw upon mimesis for the purpose of our work in relation to ekphrasis as it draws our attention to the organization of the experience, of not only the practice of paying attention to the natural world in the process of writing but also the role of photography in this multi-layered process. For example, taking a photograph while in the natural world and simultaneously documenting our response to both nature and the photograph that is revisited over time, involves a poetic response to an aesthetic form, namely a photograph. However, there is a layered response as part of the writing process that takes place while in nature, and an ongoing response 
to the photograph. This layering is complex and can lead to a rich response in which mimesis (an imitation that involves an organization of human cognition), and a response to an aesthetic form (the photograph) takes place. There is a rich body of literature on ekphrasis that we consider to be in keeping with more traditional forms of ekphrastic poetics, which informs our framework for responding to aesthetic forms through poetic writing (see Denham, 2010; Heffernan, 2004; Kennedy, 2013; Prendergast, 2004; and Young, 2006). However, we argue that our process differs from these works because it involves being in nature while photographing the aesthetic forms found in the natural world, and documenting an initial response in addition to a more traditional poetic response to the photograph taken. This layering provides a valuable experience for the learner.

We expand our idea of language learning and interpretation to include opportunities for readers and writers to observe connections with the places they live in and know through paying close attention to images. In this article, ekphrastic poetics is conceptualized as an aesthetic practice that participates in the ongoing making of human subjectivities whereby learners can develop relationships between their ever-evolving senses of self and their engagements with aesthetic ecological forms. These forms include oral and literary practices that engage human understandings with what Abram's (1996) terms the "more-than-human world."

One of the aesthetic forms we feel is particularly important is the production of collections of works to be shared and remembered in classroom communities through zines, anthologies, and so forth. Sharing one's work with others is an important part of the writing process. Jan Zwicky's (2008) Songs for Relinquishing the Earth is a good example of poetic art that was first made and distributed by the author herself. Poetic collections are a good way to help learners develop a sense of what it means to create poetic work that tells a story. As Debbie Carter (2011) points out, it is important to have parents and other extended community members as part of the process. For example, in our preservice teacher education English/language arts classrooms, students engage in writing activities over the course of the term. They are asked to revisit their work and "polish" a piece to be shared in a class collection. During the last class, we celebrate their writing through a "literary cafe"" whereby students are invited to share their writing aloud. It is wonderful to see how proud students are to see their work in print.

\section{A Project of Ekphrastic Poetics}

Since 2000, we have been working on a project of ekphrastic poetics. We have been working with several themes simultaneously, that of intergenerational knowledge and natural landscapes. As Kucer (2014) points out, "writers reach their goals by developing a series of plans" (p. 206). Rather than providing a concrete example of what learners should model their writing from, we often begin our journey of poetic inquiry with timed writing activities, designed to take students toward a research direction of their own choice. If time permits, we move beyond these preliminary activities to small-group discussions about the writing activities. Students are invited to continue their dialogue through electronic technologies (texting, email, etc.) to further explore their understandings, much as we do in our own research and poetic inquiry.

We engage with ecological knowledge from both our foremothers and forefathers as they are reproduced culturally via intergenerational practices passed down in the form of stories and culturally aesthetic practices. We are researchers living in a time of heightened ecological crisis, which influences us to turn our focus toward aesthetics embedded in the natural world. Our 
inclusion of the photo "Mirrored Sunrise" below is an example of one of the places that we have been developing a relationship with learning about the indigenous plants and the ways in which they can be used as medicine both through the collection of food and teas. We document our understandings through photographs, conditioned writing practices, and poetry in our practice of ekphrastic poetics. Not only did we create conditions for poetic response, but also we paid close attention to our practices. For example, we use our photographs of the natural world to help structure and organize our theorization about the ways in which identity and a sense of self evolve by telling our stories.

We organized our ekphrastic approach to writing poetry, for the most part, through timed writing practices, an understanding of mimesis as an imaginative practice, dwelling in natural environments (photographing/documenting), and prompted by a notion that one must become attentive to language. Being attentive to languages and literacies usually requires that words be clarified and historically traced in order for a deeper meaning to evolve. For this purpose, the word organize can be traced back to the Latin word organum (The Oxford English Dictionary, p. 192). The root of the word, organ, has a history of being associated with wind instruments made of pipes that were played in musical harmony. Organic pipes were assembled into an organized structure and systemic form. Musical harmony relied on the connectedness and coordination of its intricate parts. During the $15^{\text {th }}$ century, the meaning expanded to include body organs. The first body parts identified as organs were speech organs such as the larynx, which is a means of communication. Later, an expansive understanding of this word included any instrument or medium of communication. The word instrument and the word instruct have the same roots. From these historical definitions, the verb organize is related to structural forms, (both the parts and the whole working in harmony) and instruction (that includes learning through communication via bodily organs). We draw on this definition to further understand how the interconnectedness of language (both in the form of visual culture that is dominated by media and textual representation) and identity-formation (of a sense of self), evolves through interpretive response activities.

By interpretive response activities, we are referring to spending time in natural environments, photographing our experiences in order to allow a poetic response to emerge. For example, the following Kulnieks (2009) photograph titled, "Mirrored Sunrise" prompted the poetic response titled, "Myths of Weeds" below. 


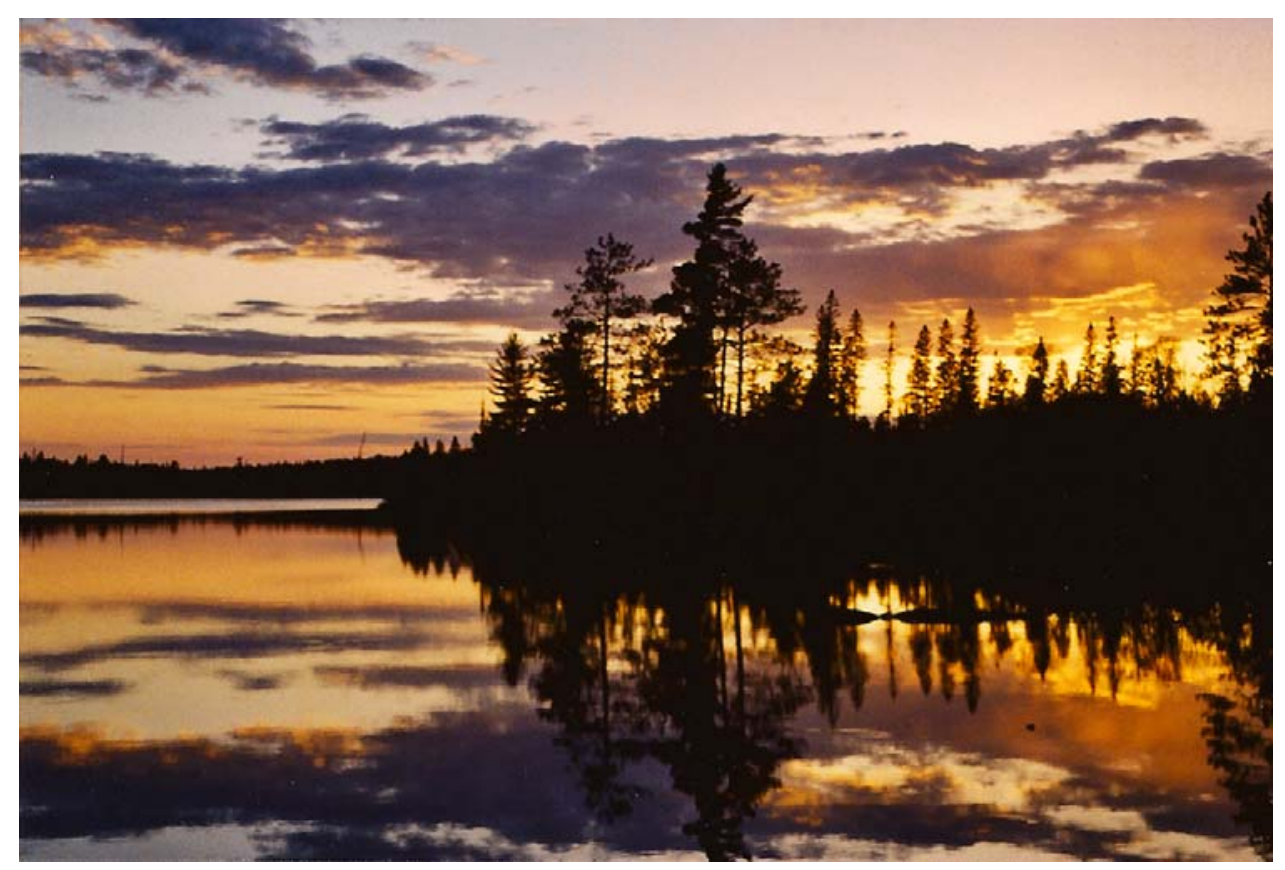

Figure 1. "Mirrored Sunrise" (Kulnieks, 2009)

Myths of Weeds

Deep in the forest of our minds

sword-shaped cattail stalks soar westward

soft-fleshed bulrushes rise above shallow marshlands

where sleeping willows rest in shadows of water lilies

primrose attracts night-flying moths

hidden in small clusters of sumac, milkweed, and wild leek

as myths of weeds crisscross long stalked Great Burduck

filling Mother Nature's pantry in a furtive profusion of versatile delicacies

time counted in seasons of food gathered and hunted

soil tilled by hands stained blue with berries

trees exchanging our air and energy

water moving information from faraway times

where wood cooks the food we eat

uncontaminated by chemicals with longer names than the food

processed by your hands that placed seeds into the earth

that gave life when dreams brought us beyond the places

where colours were learned through a landscape of life

on summer days you brought me to the hazelnuts

showed me how to take away the sting by soaking fingers with saliva

to where mushrooms peered through earth

and how to break branches for the fire

transform roots into flowers

that return each summer

(Kulnieks \&Young, 2014) 
Our poem "Myths of Weeds" tells a story of the delicateness of the earth and the importance of planting and gathering food. "Mirrored Sunrise" captures the colours of the early morning sun as the day begins. Oliver Sacks (1995) points out, colour "is a sense that interweaves itself in all our visual experiences and is so central in our imaginations and memory, our knowledge of the world, our culture and art" (p. 33). The title of the poetic response, "Myths of Weeds," evokes a sense of silent language that embodies the senses. Abram (1996) writes, "Our own speaking, then, does not set us outside of the animate landscape but - whether or not we are aware of itinscribes us more fully in its chattering, whispering soundful depths" (p. 80). Language is constituted both by silence through wordless participation and perceptual immersion in a silent yet expressive world and by sound through a poetic production of expressive speech. As Abram (1996) explains, "Language cannot be genuinely studied or understood in isolation from the sensuous reverberation and resonance o active speech" (p. 75). Drawing upon Abram's understanding of the sensorial experience, what follows is an example of our collaborative conditioned writing practices.

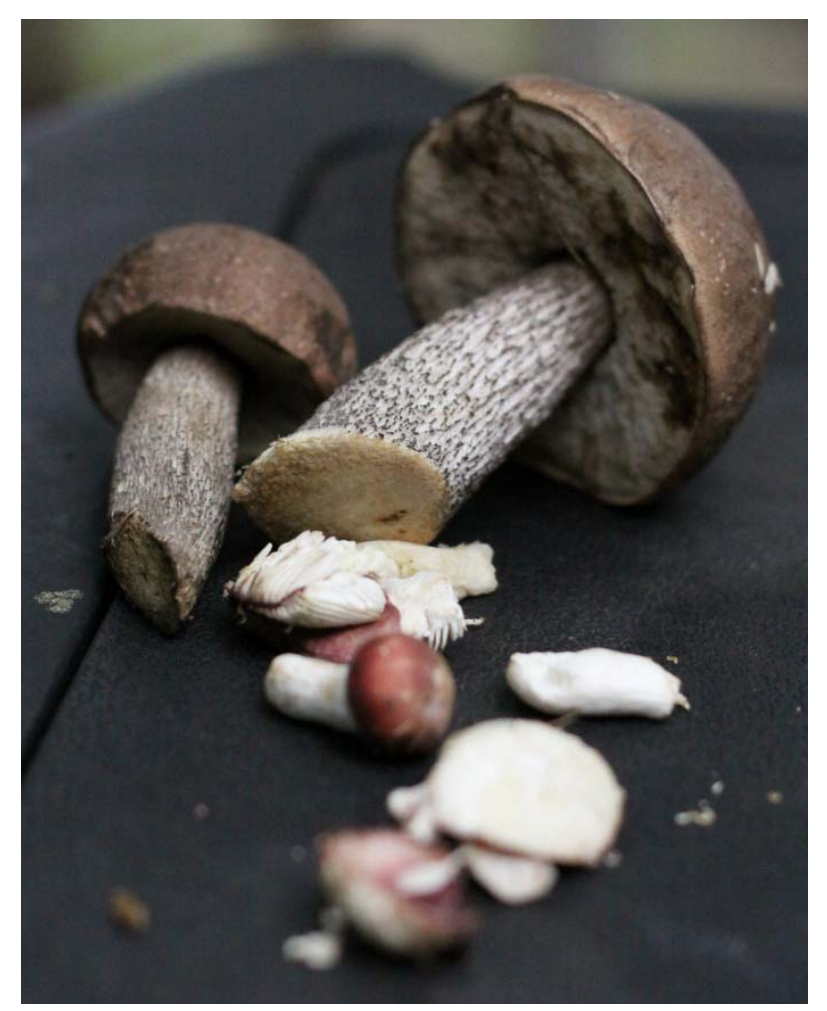

Figure 2. "Mushrooms" (Vectīrele, 2014)

\section{Earth Song}

\section{Shadows}

under wind swept dock

reveal our bodies

ebb and flow

a symbolic web

soothed by summer breeze

beneath ivy wrapped hills 
we hear a robin's lullaby

her mating call over the swollen lake

breaking the silence for the velvet night

capable wings floating homeward

far above the ground soar through the trees

as she sings a bird song

for Gaia our earth Goddess

grandmother walks forest paths

as she has during spring and fall since childhood

searching along forest and meadow paths

for mushrooms, berries and other medicines

they are part of her literacies

translated in languages

shapes, sizes, colour shades, scents

knowing being essential to life

and knowing movement along these places was healthy

and you know where

she knows where the water is

and how to help the plants thrive

along the lakes and streams

where the clear-cutting scraped the vegetation to earth and rock

(Kulnieks \&Young, 2014)

As Melissa Nelson (2008) reminds us, "The future of our individual and collective health and vitality depends on us reclaiming and creating healthy food traditions" (p. 181). Our collaborative approach to writing poetry comes from hours of spending time in natural spaces, dialogues about our understanding of intergenerational knowledge and indigenous traditional teachings that inform our pedagogical process. "Earth Song" captures much of our dialogue about the importance of what our grandmothers knew about natural landscapes, indigenous plants and medicines, and the importance of intergenerational knowledge that passes down to us through her stories and recipes. Grandmother is also a metaphorical symbol that signifies a regeneration of life.

In addition to being attentive to language as part of an ekphrastic approach to writing poetry, we focus on the importance of exploring local ecologies and the ways in which through the imagination new understandings are achieved through poetic narratives. As learners, we relate, sympathize, and identify with aesthetic, textual, and ecological forms, while participating in the practice of storytelling; ekphrastic poetics becomes a part of that work. Learners who make connections to these forms will often feel comfortable and search for deeper more detailed and meaningful interpretations as ecology plays an important role in the experience. Literary theorist, Jonathan Culler (1997) understands this response; he states, "stories, the argument goes, are the main way we make sense of things, whether in thinking of our lives as a progression leading somewhere or in telling ourselves what is happening in the world" (p. 83). Ekphrastic poetics, then, enables learners to think about their own experiences in new ways and provides a 
locale for experiencing the importance of paying attention to language, the work of interpretation, and the exploration of the ecology in natural landscapes. This conceptual activity allows for a (re)assessment of views, a (re)construction of meanings, and a move toward imaginative conceptualizations beyond lived experiences as it fosters a development of ecological habits of mind by reminding us that we are embedded and interconnected with our local ecosystem.

Our final example, "Grandmother Poem" is an example of poetic inquiry as it traces a journey, as research participant, towards a deeper understanding of developing a relationship with a particular place in Southern Ontario.

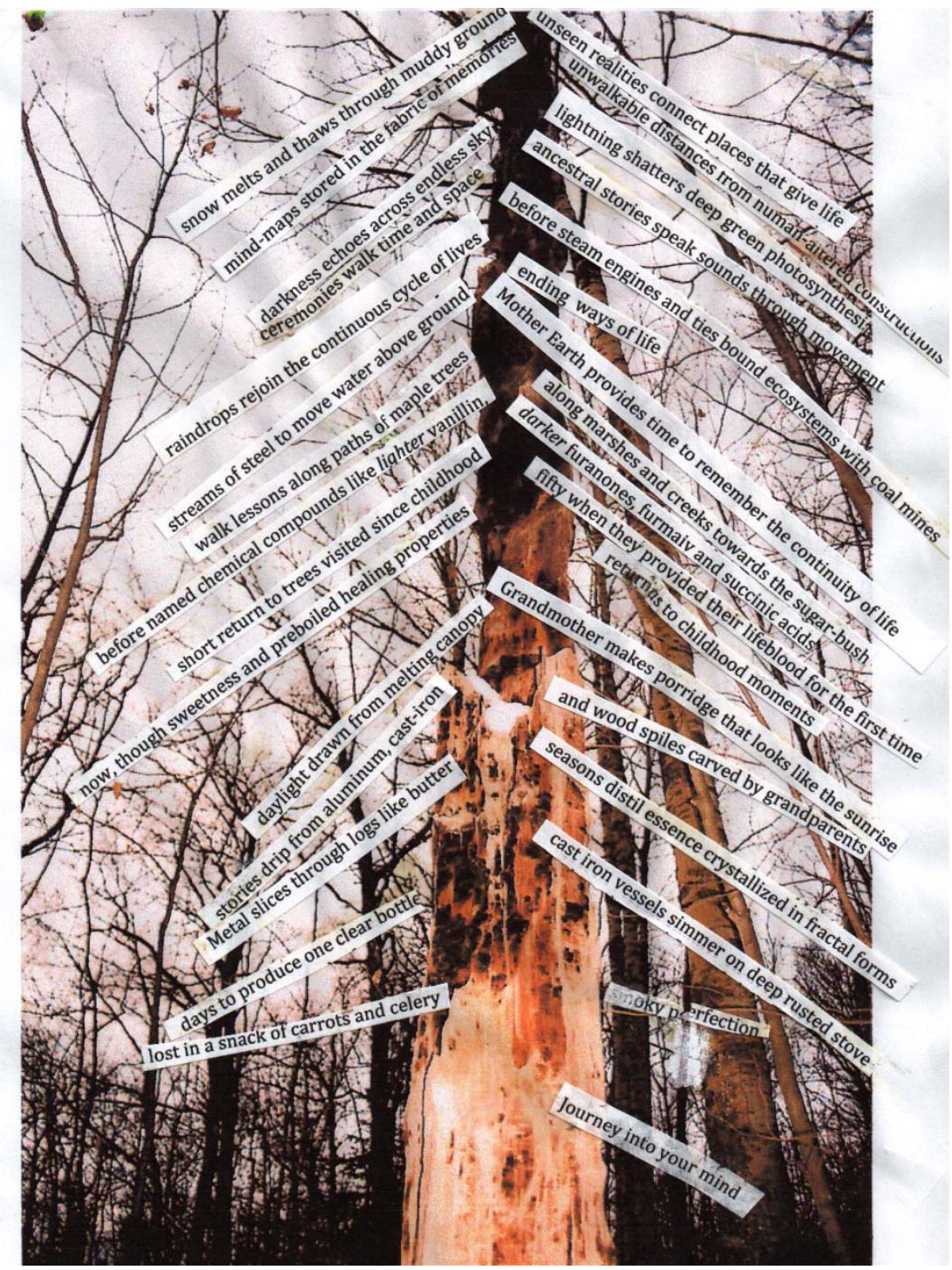

Figure 3.“Grandmother Poem” (Kulnieks, 2012)

In the "Grandmother Poem," Kulnieks (2012) traces a journey of learning how to make maple syrup as an investigation of exploring intact ecosystems. This poem began as part of an environmental autobiography many years ago. We have used this poem in graduate and undergraduate classes as well as during conference presentations as an example of developing a 
connection between images and place as a beginning space for poetic inquiry. The poem began as an inquiry into considering ancestral teachings about place and plants but evolved into research specifically regarding how maple syrup is made. It includes the chemicals that the maple syrup contains. The visual representation also outlines the cyclical transformation of life. In addition to birth and rebirth, the language that comes from the branches suggests human engagement with natural elements, for example, the dead tree. The fire imagery associated with the ancient scorched tree-trunk also points to the transformation of the tree that takes place beyond human use. The poem is an example of bringing images and poetry together. Through this process, we draw upon Linda Lambo and Tammy Ryan's (2012) research about how photography can be used in the classroom to inspire the development of language researching and learning opportunities for students: "Families, many of whom had not actively participated in school functions before, brought favourite foods, read each other's albums, and shared personal stories" (p. 100). This sharing of information in a picnic format is a way of enabling learners to make connection between their language learning and the world beyond the classroom. Connecting classroom learning about nutrition with poetic writing can also inspire an interest in the types of foods and eating habits that students and parents engage with throughout their lives by emphasizing the importance of ecology and intergenerational knowledge in learning environments.

\section{Ekphrastic Poetics in Teacher Education: Implications for Pedagogy}

We introduce the classical form of ekphrastic poetics in our teacher education classrooms framed by a discussion of the ways in which aesthetic cultural forms and the natural world play an integral part in organizing subjectivity. We model and participate in classroom writing practices in order that students have an opportunity to develop strong poetic habits of mind and perhaps to share these in their own classrooms. We encourage a dialogue about the ways in which poetry is linked to the imagination through mimesis. Mimesis, as the art of imitation, is an important part of pedagogical practices in terms of spending time observing one's surroundings. It serves as the basis for all learning: paying attention to what we are seeing around us. Mimesis symbolizes the surprising steps that can be taken along a path in becoming a stronger writer and teacher. By drawing on William Pinar's (1995) conceptualization of "curriculum as aesthetic text," we become aware of the ways in which the imagination is provoked through an affective response to visual senses. In this way, deep emotional resonance can be evoked through what artist educator, Elliot Eisner (as cited in Pinar, 1985) refers to as "four senses in which teaching can be considered an art" which we apply to the creation of eco-poetic work (p. 581). First, as a teacher of poetry, one should be accomplished in their craft because the role of artist and educator are inseparable and embodied. Second, as a teacher of poetry, we make judgements during the teaching process based on qualities discerned during the course of the process. Third, as artist and educator, we balance what Eisner terms "automacy and inventiveness" (as cited in Pinar, 1985 , p. 581) through different weekly writing exercises along a continuum of inquiry into learning to write poetry. Eisner suggests that it is the teacher who must model pedagogical practices that provoke the possibility of surprise in teaching and learning. Finally, there must be a balance of "routinized behaviours" (as cited in Pinar, 1985, p. 581) with creativity in the classroom. It is essential to create the conditions that evoke the imagination in pedagogical settings. In Pinar's (1995) words:

To understand the role of the imagination in the development of the intellect, to cultivate the capacity to know aesthetically, to comprehend the teacher and his or 
her work as inherently aesthetic: these are among aspirations of that scholarship which seeks to understand curriculum as aesthetic text. (p. 604)

We conceptualize the work of ekphrastic poetics as a curriculum and aesthetic-ecological text. By introducing new forms into teacher education classrooms such as ekphrastic poetics, learners can develop relationships between their ever-evolving senses of self and their engagements with natural aesthetic forms.

To answer our question that we posed at the beginning, "How does one begin writing a poem that connects language, place and intergenerational knowledge?", we have turned our attention to ekphrastic poetics, a classical art form, and theorized its importance as a literary form. We have ascribed to the notion that forms function to organize experiences of identityformation. The answer lies in the way in which this notion of poetry is framed. Aesthetic forms are inherently organizing phenomena that are often inspired by the natural world. By pointing to our own example of engaging in ekphrastic poetics, together with the ways in which we introduce this classical form in our teacher education classrooms, we are opening possibilities of using literary forms in the exploration of the ways in which forms organize and mediate human subjectivities. In this way, responding to visual culture involves paying attention to the natural environment, language, mimesis, the imagination, and the affective response they provoke through conditioned interpretive practices. Just as humans can form relationships with particular literary forms, they can form relationships with visual and natural forms. These relationships are important as they inform pedagogical practices and provide insight into research about our connections with local environments.

The close study of works of visual and natural relationships with intact ecosystems is important and by carefully working with one idea, such as ekphrastic poetics, new details can surface and consequently a new outlook can be evoked. Forms are influential in the ways learners experience identity and the particularity of ekphrastic poetics is interesting and relates not only to language but also to representational forms and lived experience. Since humans need forms to help them organize a sense of self, interpretative practices with ekphrastic poetics provide learners with a form to negotiate a sense of self in relation to the world. Keeping in mind that, according to Bruner (1990), this self finds itself lodged in the cultural-historical situation as well as in the private consciousness, forms are mediated and organized by language. Poetry organizes human consciousness in particular ways, and ekphrastic poetics can become one form that organizes perception and helps to foster ecological habits of mind in teacher education. 


\section{References}

Abram, D. (1996). The spell of the sensuous: Perception in a more-than-human world. New York, NY: Pantheon Books.

Bruner, J. (1990). Acts of meaning. Cambridge, MA: Harvard University Press.

Carter, D. (2011). Teachers' voices: Welcoming family collaboration. In R. Powell \& E. Rightmyer (Eds.), Literacy for all students: An instructional framework for closing the gap (pp. 71-85). New York, NY: Routledge: Taylor \& Francis.

Culler, J. (1997). Literary theory: A very short introduction. New York, NY: Oxford University Press.

Davis, B., Sumara, D., \& Luce-Kapler, R. (2000). Engaging minds: Learning and teaching in a complex world. Mahwah, NJ: Lawrence Erlbaum Associates.

Denham, R. D. (2010). Poets on painting: A bibliography. Jefferson, NC: McFarland.

Duncan-Jones, K. (Ed.). (1989). Sir Philip Sidney: A critical edition of the major works. Oxford: Oxford University Press.

Greene, M. (1995). Releasing the imagination: Essays on education, the arts, and social change. San Francisco, CA: Jossey-Bass Publishers.

Heffernan, J. A. (2004). Museum of words: The poetics of ekphrasis from Homer to Ashbery. Chicago, IL: University of Chicago Press.

Kennedy, D. (2013). The ekphrastic encounter in contemporary British poetry and elsewhere. Farnham, UK: Ashgate.

Kucer, S. (2014). Dimensions of literacy: A conceptual base for teaching reading and writing in school settings. New York, NY: Routledge, Taylor and Francis.

Kulnieks, A. (2009). Ecopoetics and the epistemology of landscape: Interpreting Indigenous and Latvian ancestral ontologies. Toronto, ON: York University. Unpublished Dissertation.

Kulnieks, A. (2012). Grandmother poem. Rampike, 21(1), p. 79 Poetics: Part One.

Kulnieks, A., \& Young, K. (2014). Ekphrastic poetics: Reflecting poetry beyond images. Unpublished Manuscript.

Lambo, L. \& Ryan, T. (2012). Traversing the "literacies" landscape: A semiotic perspective on early literacy acquisition and digital literacies instruction. In E. Baker (Ed.), The new literacies: Multiple perspectives on research and practice (pp. 88-105). New York, NY: The Guilford Press.

Nelson, M. (2008). Original instructions: Indigenous teachings for a sustainable future. Rochester, VT: Bear \& Company Publishers.

Organize. (1989). In the Oxford English Dictionary. London, England: Oxford University Press. 
Prendergast, M. (2004). Ekphrasis and inquiry: Artful writing on arts-based topics in educational research. Proceedings from the Second International Imagination in Education Research Group Conference, Simon Fraser University, Vancouver, British Columbia. Retrieved from http://www.indabook.org/preview/lTBabTVl6DXtkK9jf8G5Rf9maQmqkGgUFVuHfgJf2I,/EKPHRASIS-AND-INQUIRY-ARTFULWRITING-ON-ARTS.html?query=Inquiry-Based-Topics

Pinar, W. (1995). Understanding curriculum. New York, NY: Peter Lang.

Sacks, O. (1995). An anthropologist on Mars. New York, NY: Random House.

Turner, F. (1985, August). Cultivating the American garden: Toward a secular view of nature. Harper's Magazine, 45-52.

Vectīrele, Z. (2014). Free Entrance: Collecting stories through photographs. Unpublished Manuscript.

Young, K. (2006). The pedagogic force of ekphrastic poetics. Language and Literacy: A Canadian E-Journal, 8(2), 1-18.

Zwicky, J. (2008). Songs for relinquishing the earth. London, ON: Brick Books. 